American Journal of Applied Sciences 8 (10): 1014-1018, 2011

ISSN 1546-9239

(C) 2011 Science Publications

\title{
Static Synchronous Series Compensator Controller based on Fuzzy Logic Control for Power System Stabilization
}

\author{
Prechanon Kumkratug \\ Division of Electrical Engineering, Faculty of Engineering at Si Racha, \\ Kasetsart University, 199 M.6, Tungsukhla, Si Racha, Chonburi, 20230, Thailand
}

\begin{abstract}
Problem statement: Modern power system consists of the complicated network of transmission lines and carries heavy demand. Thus they cause in the stability problem. Approach: Static Synchronous Series Compensator (SSSC) is a power electronic based device that has the capability of controlling the power flow through a line. The series voltage injection model of SSSC is modeled into power flow equation and thus it is used to determine its control strategy. This study applies the fuzzy logic applies the SSSC to improve stability of power system. The mathematical model and control strategy of a SSSC are presented. The SSSC is represented by variable voltage injection with associate transformer leakage control to derive control strategy of SSSC. The swing curves of the three phase faulted power system without and with a SSSC is tested and compared in various cases. Results: The swing curve of the system with SSSC based fuzzy logic control has the less amplitude during the dynamic period. Conclusion: It was found from simulation results that SSSC can improve the power system oscillation after disturbance.
\end{abstract}

Key words: Static Synchronous Series Compensator (SSSC), High Voltage Direct Current (HVDC), Single Machine Infinite Bus (SMIB), derive control strategy, energy utilization point, shunt current, solid state voltage source

\section{INTRODUCTION}

From the energy utilization point of view, electricity is still being regarded as mighty means of energy carrier. Nowadays, the demand of electricity has dramatically increased and a modern power system becomes a complex network of transmission lines interconnecting the generating stations to the major loads points in the overall power system in order to support the high demand of consumers. The complicated network causes the stability problem. Transient stability improvement is one of the important aspects in modern power system (Al-Husban, 2009; Mota and Mota, 2011; Taher et al., 2008; Chen, 2011; JiaLiang et al., 2010; Magaji and Mustafa, 2009; Nisar et al., 2009). They have proposed many methods to improve stability of power system such as load shedding, High Voltage Direct Current (HVDC), Flexible AC Transmission System (FACTS).

A Static Synchronous Series Compensator (SSSC) is a member of the FACTS family that is connected in series with power system. The SSSC consists of a solid state voltage source converter with GTO thyristor switches or other high performance of semiconductor and transformer. The SSSC can electrically mimic reactor and capacitor by injecting a shunt current in quadrature with the line voltage. The reactive power (or current) of the SSSC can be adjusted by controlling the magnitude and phase angle of the output voltage of the shunt converter (Mustafa and Magaji, 2009; Kumkratug, 2011a; 2011b; El-Shennawy et al. 2010).

This study presents the fuzzy logic control law of SSSC. The mathematical model of power system equipped with a SSSC is systematically derived. The nonlinear control of fuzzy logic control is applied to determine the control strategy. The simulation results are tested on a sample system.

\section{MATERIALS AND METHODS}

Mathematical model: Figure 1a shows the single line diagram of Single Machine Infinite Bus (SMIB) system without a SSSC and the corresponding equivalent circuit is shown in Fig. 1b. Here $X_{1}$ is the equivalent reactance between the machine internal bus and the bus $\mathrm{m}$ and $\mathrm{X}_{2}$ is the equivalent reactance between bus $m$ and the infinite bus. The generator is represented by a constant voltage source ( $\left.E^{\prime}\right)$ behind transient reactance $\left(\mathrm{X}_{\mathrm{d}}{ }_{\mathrm{d}}\right)$.

Consider the system without a SSSC as shown in Fig. 1, the line current is given by Eq. 1 and 2: 


$$
\begin{aligned}
I_{0} & =\frac{E^{\prime}-V_{b}}{j X} \\
& =\frac{\left(E^{\prime} \cos \delta+j E^{\prime} \sin \delta\right)-\left(V_{b}\right)}{j X} \\
& =\left(\frac{E^{\prime}}{X} \sin \delta\right)+j\left(-\frac{E^{\prime}}{X} \cos \delta+\frac{V_{b}}{X}\right)
\end{aligned}
$$

Here $X=X_{1}+X_{2}$ :

$$
\theta=\tan ^{-1}\left[\frac{\mathrm{V}_{\mathrm{b}}-\mathrm{E}^{\prime} \cos \delta}{\mathrm{E}^{\prime} \sin \delta}\right] \mathbb{Z}
$$

The output electrical power of the system without a SSSC is given by Eq. 3:

$$
\mathrm{P}_{\mathrm{e}}^{0}=\frac{\mathrm{E}^{\prime} \mathrm{V}_{\mathrm{b}}}{\mathrm{X}} \sin \delta
$$

Now, consider the system with a SSSC as shown in Fig. 2. The Fig. $2 \mathrm{~b}$ represents the equivalent circuit of Fig. 2a. The SSSC is represented by a series voltage injection $\left(\mathrm{V}_{\mathrm{s}}\right)$ and transformer leakage reactance. From Fig. 2b, the line current of the system with a SSSC is given by:

$$
\mathbf{I}_{\mathrm{ss}}=\frac{\mathbf{E}^{\prime}-\mathbf{V}_{\mathrm{s}}-\mathrm{V}_{\mathrm{b}}}{\mathrm{jX}}=\left[\frac{\mathbf{E}^{\prime}-\mathrm{V}_{\mathrm{b}}}{\mathrm{jX}}\right]+\left[\frac{-\mathbf{V}_{\mathrm{s}}}{\mathrm{jX}}\right]
$$

From the Eq. 1 and Eq. 4, the line current of the system with a SSSC is given by Eq. 5 :

$$
\mathbf{I}_{\mathrm{ss}}=\mathbf{I}_{0}+\Delta \mathbf{I}
$$

Here:

$$
\Delta \mathbf{I}=\frac{-\mathbf{V}_{\mathrm{s}}}{\mathrm{jX}}
$$

From Eq. 1 and 4, $\Delta \mathrm{I}$ is the additional component of the system of a SSSC. The output electrical power equation of generator can be expressed by Eq. 6:

$$
\begin{aligned}
\mathrm{P}_{\mathrm{e}}^{\mathrm{ss}} & =\operatorname{Re}\left[\mathbf{E}^{\prime}\left(\mathbf{I}_{\mathrm{ss}}\right)^{*}\right] \\
& =\operatorname{Re}\left[\mathbf{E}^{\prime}\left(\mathbf{I}_{\mathbf{0}}\right)^{*}\right]+\operatorname{Re}\left[\mathbf{E}^{\prime}(\Delta \mathbf{I})^{*}\right]
\end{aligned}
$$

The first term of Eq. 6 represents the system without a SSSC. The second term is the additional component from the $\operatorname{SSSC}\left(\Delta \mathrm{P}_{\mathrm{e}}^{\mathrm{ss}}\right)$ rewritten by Eq. 7

$\mathrm{P}_{\mathrm{e}}^{\mathrm{ss}}=\mathrm{P}_{\mathrm{e}}+\Delta \mathrm{P}_{\mathrm{e}}^{\mathrm{ss}}$

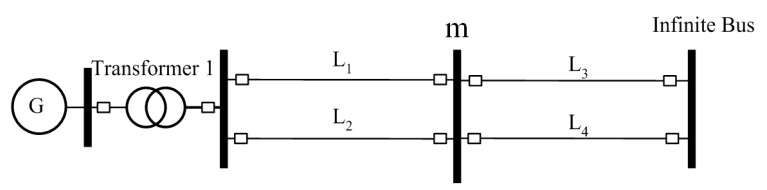

(a)

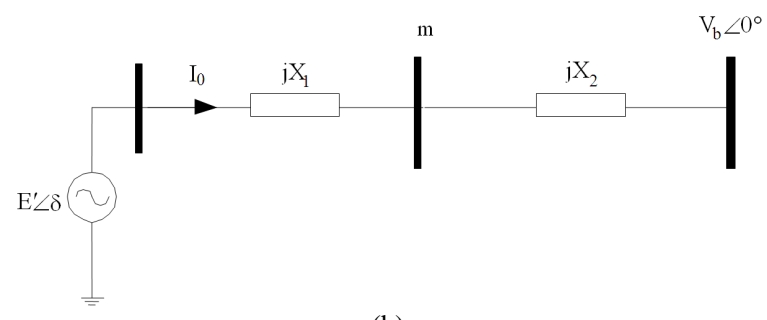

(b)

Fig. 1: Single machine infinite bus system (a) schematic diagram (b) equivalent circuit

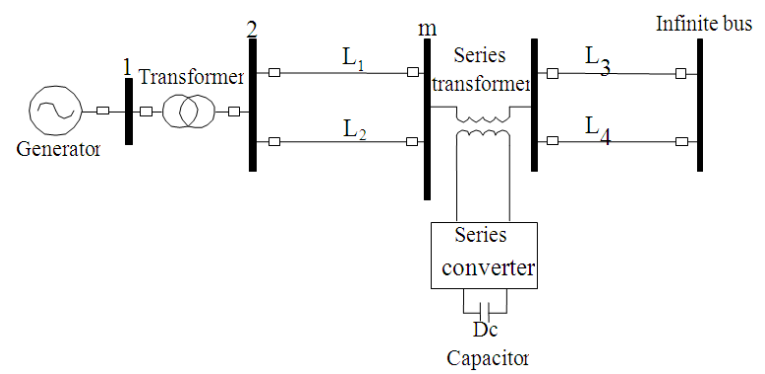

(a)

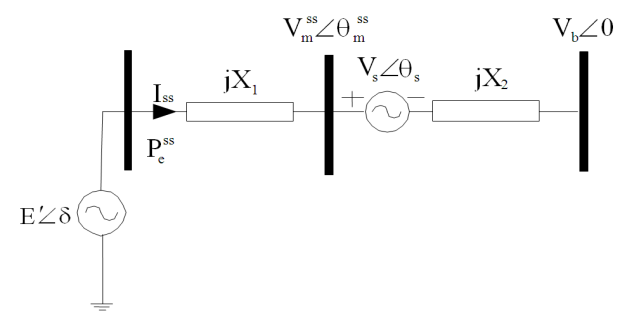

(b)

Fig. 2: Single machine infinite bus system with a SSSC (a) schematic diagram (b) equivalent circuit of system with a SSSC represented by a series voltage injection

The $\Delta \mathrm{P}^{\mathrm{ss}}$ is written by Eq. 8:

$$
\begin{aligned}
\Delta \mathrm{P}_{\mathrm{e}}^{\mathrm{ss}} & =\operatorname{Re}\left[\mathbf{E}^{\prime}\left(\frac{-\mathbf{V}_{\mathrm{s}}}{\mathrm{j} \mathrm{X}_{2}}\right)^{*}\right] \\
& =\operatorname{Re}\left[\mathrm{E}^{\prime} \angle \delta\left(\frac{-\mathrm{V}_{\mathrm{s}} \angle \theta_{\mathrm{s}}}{\mathrm{jX}}\right)^{*}\right] \\
& =\frac{\mathrm{E}^{\prime} \mathrm{V}_{\mathrm{s}}}{\mathrm{X}} \sin \left(\delta-\theta_{\mathrm{s}}\right)
\end{aligned}
$$


Am. J. Applied Sci., 8 (10): 1014-1018, 2011

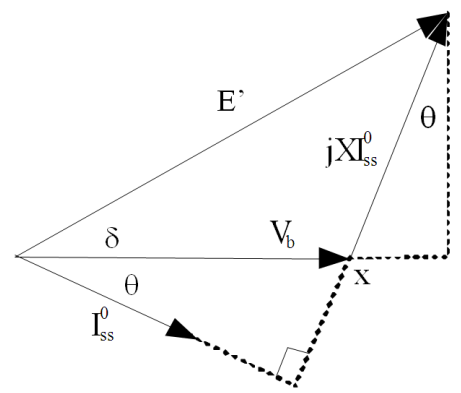

(a)

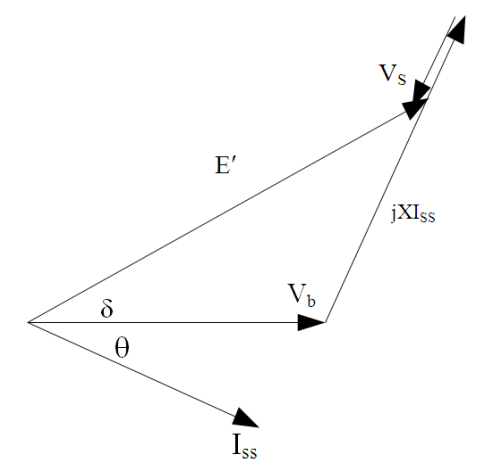

(b)

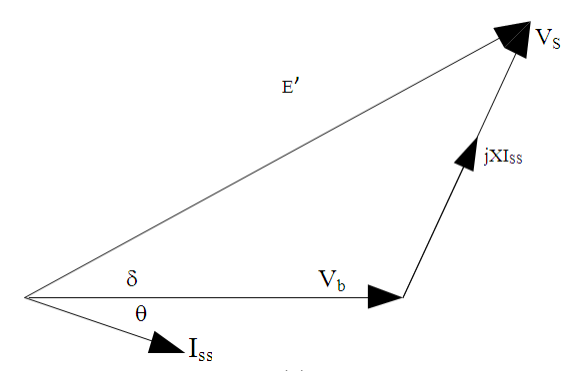

(c)

Fig. 3: Phasor diagram (a) without a SSSC (b) with a SSSC operating in capacitive mode (c) with a SSSC operating in reactive mode

When $\mathrm{V}_{\mathrm{s}}$ is positive, the SSSC supplies the reactive power to the system, it is called capacitive mode and then the series voltage angle $\theta_{\mathrm{s}}$ is in lagging with the line current as shown in Fig. $3 \mathrm{~b}$ whereas $\mathrm{V}_{\mathrm{s}}$ is negative, the SSSC absorbs the reactive power to the system, it is called reactive mode and then the series voltage angle $\theta_{\mathrm{s}}$ is in leading with the line current as shown in Fig. 3c. With the capacitive mode the Eq. 8 is given by Eq. 9:

$$
\Delta \mathrm{P}_{\mathrm{e}}^{\mathrm{ss}}=\frac{\mathrm{E}^{\prime} \mathrm{V}_{\mathrm{s}}}{\mathrm{X}} \cos (\delta-\theta)
$$

From the Eq. 2, it can be written by:
$\mathrm{E}^{\prime} \sin \delta \sin \theta=\mathrm{V}_{\mathrm{b}} \cos \theta-\mathrm{E}^{\prime} \cos \delta \cos \theta$

With some mathematical manipulations of Eq. 10, it can be written by Eq. 11:

$\cos (\delta-\theta)=\frac{V_{\mathrm{b}}}{\mathrm{E}^{\prime}} \cos (\theta)$

From the phasor diagram as shown in Fig. 3, it indicates that the SSSC doesn't change the line current angle. However, the SSSC affects on the line current magnitude. When $\mathrm{V}_{\mathrm{s}}$ lags line current 90 degree, the line current magnitude is increased and when $\mathrm{V}_{\mathrm{s}}$ leads line current 90 degree, the line current magnitude is decreased as can be seen in Fig. 3.

From the Fig. 3, the cosine of the line current angle is given by Eq. 12:

$$
\cos (\theta)=\frac{E^{\prime} \sin (\delta)}{x y}=\frac{E^{\prime} \sin (\delta)}{\sqrt{\left(E^{\prime}\right)^{2}+\left(V_{b}\right)^{2}-2 E^{\prime} V_{b} \cos (\delta)}}
$$

From Eq. 9 and 12, the additional component of output electrical power is:

$$
\Delta \mathrm{P}_{\mathrm{e}}^{\mathrm{ss}}=\frac{\mathrm{V}_{\mathrm{s}} \mathrm{E}^{\prime} \mathrm{V}_{\mathrm{b}}}{\mathrm{X} \sqrt{\left(\mathrm{E}^{\prime}\right)^{2}+\left(\mathrm{V}_{\mathrm{b}}\right)^{2}-2 \mathrm{E}^{\prime} \mathrm{V}_{\mathrm{b}} \cos \delta}} \sin \delta
$$

From Eq. 7 and 13, the output electrical power of system with a SSSC is given by:

$$
\mathrm{P}_{\mathrm{e}}^{\mathrm{ss}}=\mathrm{P}_{\mathrm{e}}+\frac{\mathrm{V}_{\mathrm{s}} \mathrm{P}_{\mathrm{e}}}{\sqrt{\left(\mathrm{E}^{\prime}\right)^{2}+\left(\mathrm{V}_{\mathrm{b}}\right)^{2}-2 \mathrm{E}^{\prime} \mathrm{V}_{\mathrm{b}} \cos \delta}}
$$

It can be seen from Eq. 14 that the output electrical power flow can be controlled by a SSSC. With positive value of $\mathrm{V}_{\mathrm{s}}$, the output electrical power is increased whereas with negative value of $\mathrm{V}_{\mathrm{s}}$, the output electrical power is reduced.

Fuzzy logic control: The transient stability of power system as shown in Fig. 2a can be expressed by following Eq. 15 and 16:

$$
\begin{aligned}
& \dot{\delta}=\omega \\
& \dot{\omega}=\frac{1}{M}\left[\mathrm{P}_{\mathrm{m}}-\mathrm{P}_{\mathrm{e}}^{\mathrm{ss}}\right]
\end{aligned}
$$

Here $\delta, \omega$ and $\mathrm{P}_{\mathrm{m}}$ are the rotor angle, speed, mechanical input power and moment of inertia, respectively of machine. 
Figure 4 shows the machine speed of system after disturbance. Figure 5 shows the input and the output fuzzy membership function based on fuzzy logic control, respectively. The machine speed at pre-fault is considered as reference at zero value $(\omega=0)$. This study uses the rules based on human reasoning of Mamdani inference engine. Rules are defined as follows:

- If $\omega$ is positive big then $\mathrm{V}_{\mathrm{s}}$ is positive big

- If $\omega$ postive then $V_{s}$ is positive

- If $\omega$ zero then $V_{\mathrm{s}}$ is zero

- If $\omega$ negative then $V_{s}$ is negative

- If $\omega$ negative big then $\mathrm{V}_{\mathrm{s}}$ is negative big

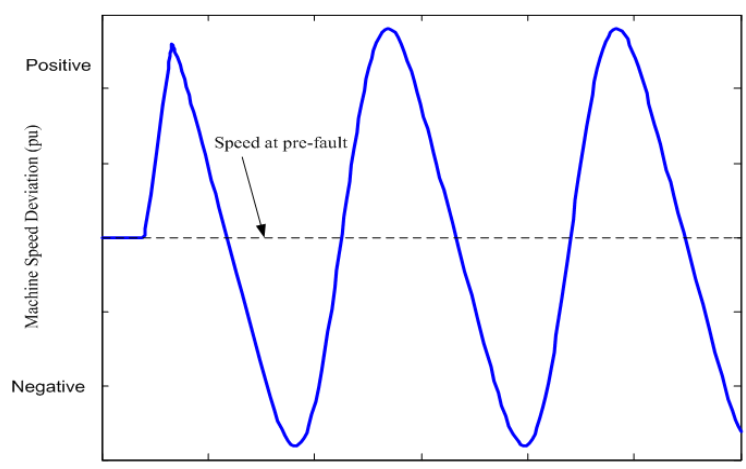

Fig. 4: Machine speed of system after disturbance

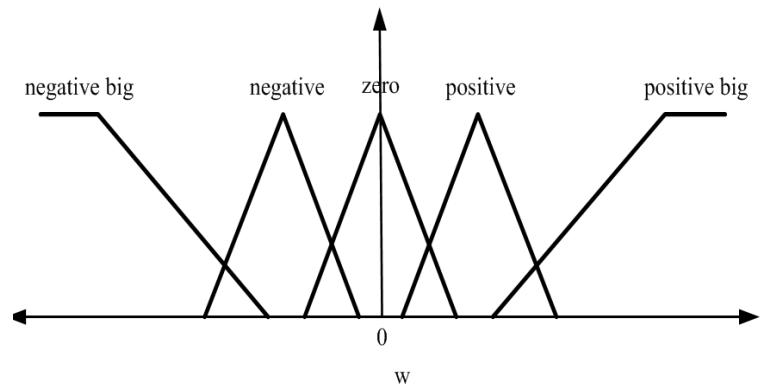

(a)

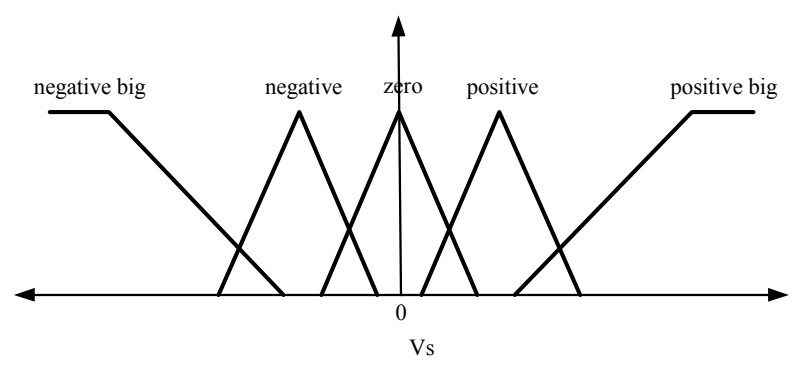

(b)

Fig. 5: Membership functions (a) Input (b) Output

\section{RESULTS}

The proposed control method is tested on sample system equipped with a SSSC based fuzzy logic control strategy. The single line diagram of sample system is shown in Fig. 2a. The system parameters are:

$\mathrm{H}=6.5, \mathrm{X}_{\mathrm{t}}=0.1 \mathrm{pu}, \mathrm{X}_{\mathrm{d}}^{\prime}=0.3 \mathrm{pu}, \mathrm{X}_{\mathrm{L} 1}=0.4 \mathrm{pu}$,

$\mathrm{X}_{\mathrm{L} 2}=0.4 \mathrm{pu}, \mathrm{X}_{\mathrm{L} 3}=0.4 \mathrm{pu}$,

$\mathrm{X}_{\mathrm{L} 4}=0.4 \mathrm{pu}, \mathrm{P}_{\mathrm{m}}=1.0 \mathrm{pu}, \mathrm{E}_{\mathrm{q}}^{\prime}=1.23 \mathrm{pu}$

It is considered that 3 phase fault appears at line 1 near bus $\mathrm{m}$ for $150 \mathrm{~m} \mathrm{sec}$ and then it is cleared by opening both circuit breakers. Figure 6 shows the machine speed of sample system without FACTS devices for generating the fuzzy membership of input $\omega$ and output $\mathrm{V}_{\mathrm{s}}$ as shown in Fig. 7a and b, respectively. Figure 8 shows the swing curve of the system without and with a SSSC.

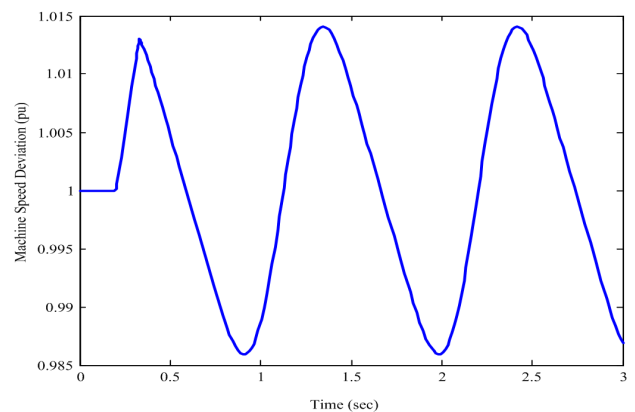

Fig. 6: Machine speed of sample system

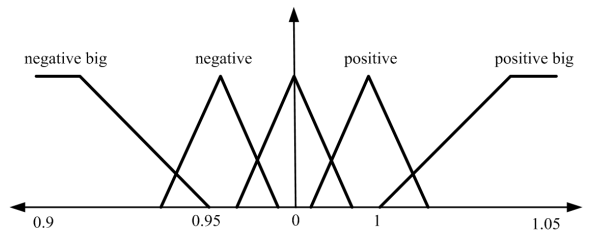

(a)

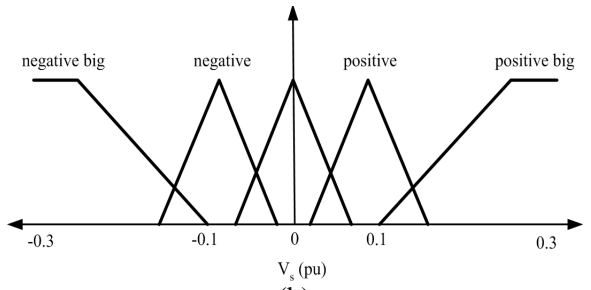

(b)

Fig. 7: Membership functions of fuzzy membership (a) Input (b) Output 


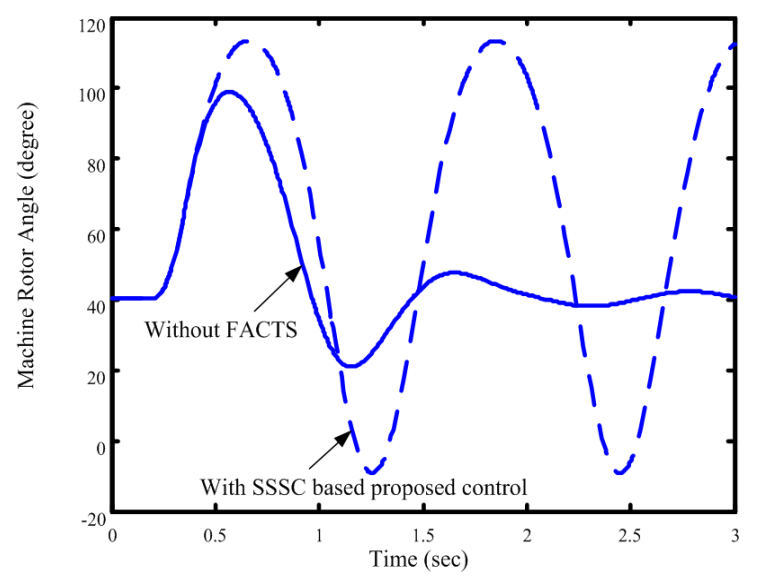

Fig. 8: Swing curve of the system without and with a SSSC

\section{DISCUSSION}

It can be observed from the simulation results that the SSSC based fuzzy logic control can improve power system oscillation. The maximum and minimum machine rotor angles are around 113.44 and -9.13 , respectively. However, maximum and minimum machine rotor angles are improved to around 98.92 and 20.98, respectively.

\section{CONCLUSION}

This study presented the method of improving power system oscillation using a SSSC. The mathematical model of power system equipped with a SSSC was systematically derived. It was found that a SSSC affects on the line voltage. The stability of the power system can be controlled by a SSSC. This study applied fuzzy logic control to determine the control law of SSSC. The simulation results are tested on a sample system. From the simulation results, it indicates that a SSSC based fuzzy logic control can improve the power system oscillation.

\section{REFERENCES}

Al-Husban, A.N., 2009. An eigenstructure assignment for a static synchronous compensator. Am. J. Eng. Applied Sci., 2: 812-816. DOI: 10.3844/ajeassp.2009.812.816
Chen, G., 2011. Dynamic optimal power flow in FSWGs integrated power system. Inform. Technol. J., 10: 385-393.

El-Shennawy, T.I., A.M. Moussa, M.A. El-Gammal and A.Y. Abou-Ghazala, 2010. A dynamic voltage restorer for voltage sag mitigation in a refinery with induction motors loads. Am. J. Eng. Applied Sci., 3: 144-151. DOI: 10.3844/ajeassp.2010.144.151

Jia-Liang, G., Z. Hong-Xia and Z. Jin, 2010. Fuzzy logic based current control schemes for vectorcontrolled asynchronous motor drives. Inform. Technol. J., 9: 1495-1499. DOI: 10.3923/itj.2010.1495.1499

Kumkratug, P., 2011a. Nonlinear control design of series FACTS devices for damping power system oscillation. Am. J. Applied Sci., 8: 124-128. DOI: 10.3844/ajassp.2011.124.128

Kumkratug, P., 2011b. Improving power system transient stability with static synchronous series compensator. Am. J. Applied Sci., 8: 77-81. DOI: 10.3844/ajassp.2011.77.81

Magaji, M. and M.W. Mustafa, 2009. Optimal thyristor control series capacitor neuro-controller for damping oscillations. J. Comput. Sci., 5: 980-987. DOI: $10.3844 /$ jcssp.2009.980.987

Mota, A.A. and L.T.M. Mota, 2011. Drawing meshed one-line diagrams of electric power systems using a modified controlled spring embedder algorithm enhanced with geospatial data. J. Comput. Sci., 7: 234-241. DOI: 10.3844/jcssp.2011.234.241

Mustafa, M.W. and N. Magaji, 2009. Optimal location of static var compensator device for damping oscillations. Am. J. Eng. Applied Sci., 2: 353-359. DOI: 10.3844/ajeassp.2009.353.359

Nisar, M.W., Y.J. Wang, M. Elahi and I.A. Khan, 2009. Software development effort estimation using fuzzy logic. Inform. Technol. J., 8: 347-353.

Taher, S.A., R. Hematti and M. Nemati, 2008. Comparison of different control strategies in GAbased optimized UPFC controller in electric power systems. Am. J. Eng. Applied Sci., 1: 45-52. DOI: 10.3844/ajeassp.2008.45 